\section{(1) \\ CrossMark}

\title{
Delphi consensus recommendations for a treatment algorithm in pulmonary sarcoidosis
}

\author{
Franck F. Rahaghi ${ }^{1}$, Robert P. Baughman ${ }^{2}$, Lesley Ann Saketkoo ${ }^{3}$, \\ Nadera J. Sweiss $\mathbb{1}^{4}$, Joseph B. Barney ${ }^{5}$, Surinder S. Birring ${ }^{6}$, Ulrich Costabel ${ }^{7}$, \\ Elliott D. Crouser ${ }^{8}$, Marjolein Drent ${ }^{9}$, Alicia K. Gerke ${ }^{10}$, Jan C. Grutters ${ }^{9}$, \\ Nabeel Y. Hamzeh ${ }^{10}$, Isham Huizar ${ }^{11}$, W. Ennis James IV ${ }^{12}$, Sanjay Kalra ${ }^{13}$, \\ Susanna Kullberg ${ }^{14}$, Huiping Li (1) ${ }^{15}$, Elyse E. Lower ${ }^{2}$, Lisa A. Maier ${ }^{16}$, \\ Mehdi Mirsaeidi ${ }^{17}$, Joachim Müller-Quernheim ${ }^{18}$, Eva M. Carmona Porquera ${ }^{13}$, \\ Lobelia Samavati ${ }^{19}$, Dominique Valeyre ${ }^{20}$ and Mary Beth Scholand ${ }^{21}$
}

@ERSpublications

Expert consensus recommendations for a pulmonary sarcoidosis treatment algorithm from a modified Delphi process include corticosteroids as initial therapy, immunomodulators for steroid-sparing or severe disease, and biologics for very severe disease http://bit.ly/2SmP3uG

Cite this article as: Rahaghi FF, Baughman RP, Saketkoo LA, et al. Delphi consensus recommendations for a treatment algorithm in pulmonary sarcoidosis. Eur Respir Rev 2020; 29: 190146 [https://doi.org/ $10.1183 / 16000617.0146-2019]$.

ABSTRACT Pulmonary sarcoidosis presents substantial management challenges, with limited evidence on effective therapies and phenotypes. In the absence of definitive evidence, expert consensus can supply clinically useful guidance in medicine. An international panel of 26 experts participated in a Delphi process to identify consensus on pharmacological management in sarcoidosis with the development of preliminary recommendations. The modified Delphi process used three rounds. The first round focused on qualitative data collection with open-ended questions to ensure comprehensive inclusion of expert concepts. Rounds 2 and 3 applied quantitative assessments using an 11-point Likert scale to identify consensus.

Key consensus points included glucocorticoids as initial therapy for most patients, with non-biologics (immunomodulators), usually methotrexate, considered in severe or extrapulmonary disease requiring prolonged treatment, or as a steroid-sparing intervention in cases with high risk of steroid toxicity. Biologic therapies might be considered as additive therapy if non-biologics are insufficiently effective or are not tolerated with initial biologic therapy, usually with a tumour necrosis factor- $\alpha$ inhibitor, typically infliximab.

The Delphi methodology provided a platform to gain potentially valuable insight and interim guidance while awaiting evidenced-based contributions.

\section{Introduction}

Sarcoidosis is a systemic granulomatous disease of unknown aetiology and heterogenous in presentation and severity $[1,2]$. It predominantly occurs with pulmonary, lymph node, skin and/or ocular involvement, but may affect virtually any organ [3]. The epidemiology of sarcoidosis varies by geography and patient population, with reported incidence ranging from 2.3 to 17.8 cases per 100000 and prevalence ranging from 2.17 to 160 cases per 100000 in studies from 2015-2017 [4-11]. Sarcoidosis is associated with an incidence and prevalence of eight and 60 cases per 100000 per year, respectively, with an estimated 25000 cases of

This article has supplementary material available from err.ersjournals.com

Provenance: Publication of this peer-reviewed article was sponsored by Mallinckrodt Pharmaceuticals, UK (principal sponsor, European Respiratory Review issue 155).

Received: 05 Nov 2019 | Accepted after revision: 07 Feb 2020

Copyright $\odot$ ERS 2020. This article is open access and distributed under the terms of the Creative Commons Attribution Non-Commercial Licence 4.0. 
sarcoidosis diagnosed in the USA each year [5]. Sarcoidosis resolves spontaneously in up to one-third of patients without therapy depending on geography and genetic factors [12, 13]. Some patients develop chronic or progressive obliterative fibrotic disease, causing significant morbidity and mortality $[3,14]$.

Few randomised controlled clinical trials exist for sarcoidosis, along with little understanding of the severity of phenotypes and sub-group response differences, making management of pulmonary sarcoidosis challenging [15]. Current recommendations suggest use of oral glucocorticoids as first-line therapy, with implementation of non-biologic and biologic immunomodulatory therapies used primarily as steroid-sparing therapies and/or to treat steroid-refractory disease [16-19].

We undertook an investigation of experts' treatment practices in sarcoidosis using Delphi consensus methodology [20-25]. We assessed these practices for areas of expert agreement that could be used for provisional guidance in therapeutic agents, dose, treatment duration and disease severity.

\section{Methods}

The study design was conceived by R.P. Baughman and F.F. Rahaghi, who met with M.B. Scholand, N.J. Sweiss and L.A. Saketkoo using the nominal group consensus technique to develop the Delphi content and design and to identify potential panellists. The Delphi method uses a series of questionnaires to facilitate consensus building among experts within certain topic areas. A common modification to the Delphi process includes the development of a qualitative, open-ended first questionnaire based on extensive review of published literature and expert opinion. In this study, a modified Delphi process (figure 1) was designed in three rounds of questionnaires, which were emailed to panellists in sequence.

Delphi panellists with international recognition as clinical experts in treatment of sarcoidosis were recruited by R.P. Baughman, F.F. Rahaghi, M.B. Scholand, N.J. Sweiss and L.A. Saketkoo with a target panel size of 15-30 members. The panel of experts was recruited from those known to have a particular interest in sarcoidosis including having a clinic or having published studies on the topic area. Experts from around the world were invited, however, not all those invited agreed to participate. Panellists were asked to rate their agreement with question statements using an 11-point Likert scale from -5 (strongly disagree) to +5 (strongly agree). Consensus was defined a priori as either a mean Likert score $\geqslant 2.5$ or $\leqslant-2.5$ signifying either consensus "for" or "against" the statement, respectively, with standard deviation not crossing zero. Scores $>-2.5$ and $<2.5$ indicate no consensus.

Questionnaire 1 was developed by R.P. Baughman, F.F. Rahaghi, M.B. Scholand, N.J. Sweiss and L.A. Saketkoo based on clinical trial evidence, publications and clinical experience, and requested qualitative data collection with open-ended questions to ensure comprehensive inclusion of expert concepts for Delphi rounds 2 and 3. Questionnaire 2 was compiled by R.P. Baughman and F.F. Rahaghi and comprehensively incorporated the anonymised qualitative concepts from Questionnaire 1. Both Questionnaires 1 and 2 allowed ongoing opportunity for respondent commentary and clarification. Questionnaire 3 contained items from Questionnaire 2. Each item in the questionnaire was displayed with the panellist's prior response in Questionnaire 2 and the mean $\pm \mathrm{SD}$ of the group's response in Questionnaire 2. This strategy has been used in previous Delphi studies to help reinforce consensus [26-30]. The final results were circulated to all panellists for review and comment.

Panellist anonymity was maintained throughout the process. All comments were incorporated anonymously in the statements and questionnaires distributed to panellists in each round.

\section{Results}

A total of 26 experts from seven countries participated in the Delphi process (table 1). As detailed by the qualifications in table 1, the panellists had a range of experience and specialty training. The final Delphi

Affiliations: ${ }^{1}$ Cleveland Clinic Florida, Weston, FL, USA. ${ }^{2}$ University of Cincinnati Medical Center, Cincinnati, $\mathrm{OH}$, USA. ${ }^{3}$ Tulane University School of Medicine, New Orleans, LA, USA. ${ }^{4}$ University of Illinois at Chicago College of Medicine, Chicago, IL, USA. ${ }^{5}$ University of Alabama at Birmingham, Birmingham, AL, USA. ${ }^{6}$ King's College Hospital, London, UK. ${ }^{7}$ Ruhrlandklinik, Essen, Germany. ${ }^{8}$ The Ohio State University, Wexner Medical Center, Columbus, OH, USA. 'ILD Center of Excellence, St. Antonius Hospital, Nieuwegein, The Netherlands. ${ }^{10}$ University of lowa Carver College of Medicine, lowa City, IA, USA. ${ }^{11}$ Texas Tech University, Health Sciences Center, Lubbock, TX, USA. ${ }^{12}$ Medical University of South Carolina College of Medicine, Charleston, SC, USA.

${ }^{13}$ Mayo Clinic, Rochester, MN, USA. ${ }^{14}$ Karolinska University Hospital, Solna, Sweden. ${ }^{15}$ Shanghai Pulmonary Hospital, Tongji University School of Medicine, Shanghai, China. ${ }^{16}$ National Jewish Health, Denver, CO, USA.

${ }^{17}$ University of Miami Miller School of Medicine, Miami, FL, USA. ${ }^{18}$ University Hospital Freiburg, Freiburg, Germany. ${ }^{19}$ Wayne State University School of Medicine, Detroit, MI, USA. ${ }^{20}$ University of Paris-Nord, Saint-Denis, France. ${ }^{21}$ University of Utah Medical Center, Salt Lake City, UT, USA.

Correspondence: Robert P. Baughman, University of Cincinnati Medical Center, 1001 Holmes Building, 200 Albert Sabin Way, Cincinnati, OH 45267, USA. E-mail: baughmrpducmail.uc.edu 


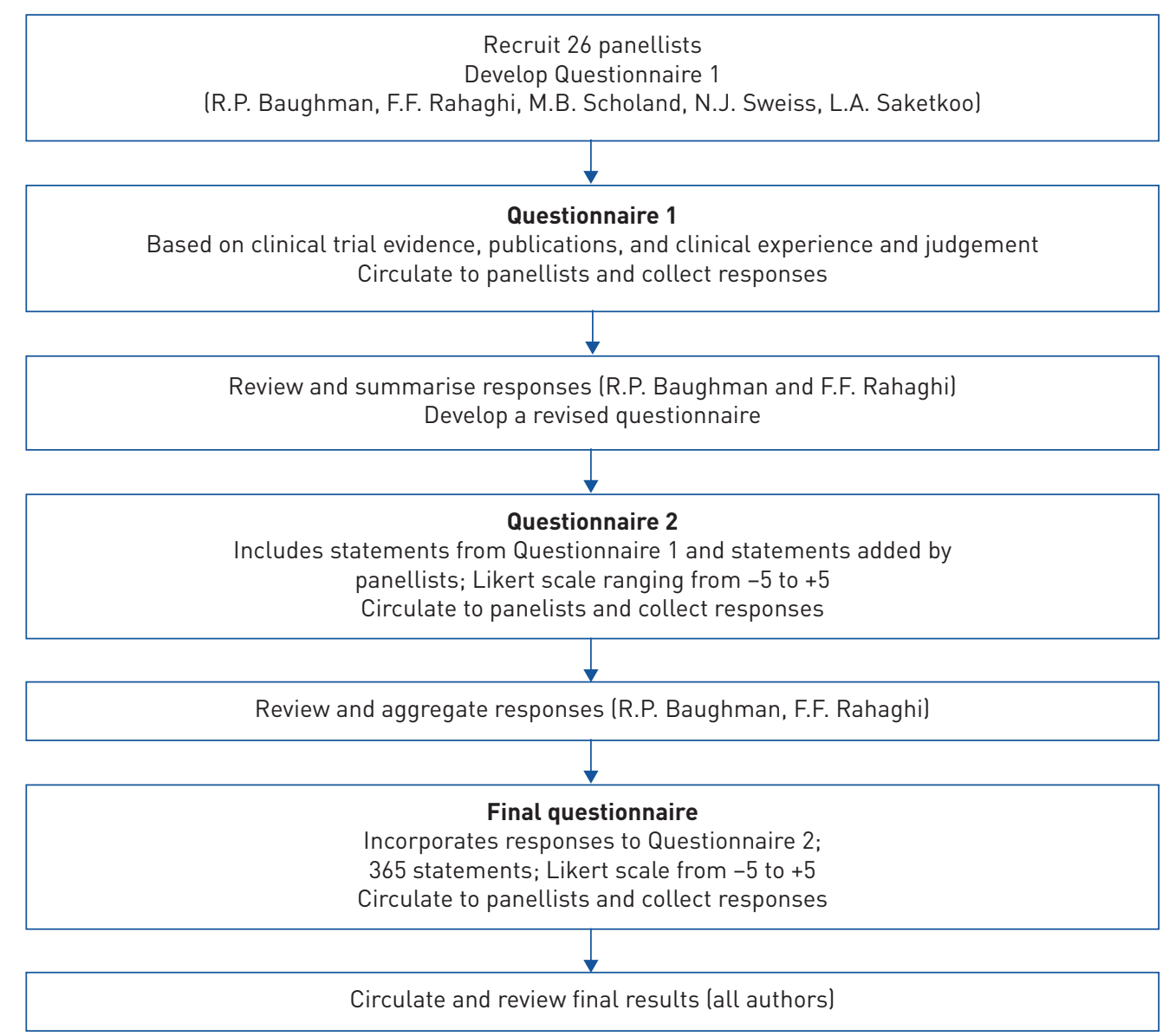

FIGURE 1 The modified Delphi process used in the study.

questionnaire contained 365 statements in five major topic areas. Consensus was reached on 183 (50.1\%) statements, with 155 and 28 statements receiving consensus "for" and "against", respectively. The final questionnaire and aggregated results are available in the supplementary material.

\section{Corticosteroids}

The panellists reached consensus on oral glucocorticoids as first-line therapy, unless contraindications existed (3.14 \pm 2.32 ), with initial dose between 20 to $40 \mathrm{mg}$ daily (4.05 \pm 0.95$)$, and dose reductions as

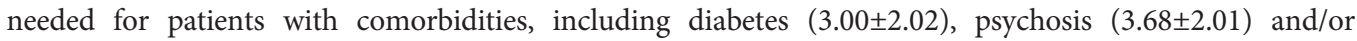
osteoporosis $(2.55 \pm 1.97)$ (figure 2 ). There was no consensus on adjustments of the initial dose for obesity or for the presence of severe symptoms, progressive disease, extensive disease or extrapulmonary involvement. Though 3-6 months was the most favoured interval for follow-up after steroid initiation (1.91 \pm 2.69$)$, no consensus was developed.

Key consensus items for worsening included adding adjunctive therapy $(4.14 \pm 1.08)$ or consideration of alternative diagnoses $(4.23 \pm 1.38)$. The consensus item for stable or improved disease was dose reduction to the lowest dose that provides satisfactory symptom relief and disease control $(3.36 \pm 1.84$ and $4.18 \pm 0.85$ for stable and improved disease, respectively). Intolerance (4.14 \pm 0.83$)$, toxicity $(4.27 \pm 1.55)$ and lack of efficacy/response $(3.41 \pm 1.99)$ were reasons to wean off steroids. Consensus developed that 3-6 months should be allowed for therapeutic response (3.74 \pm 1.55$)$, with a lack of response over 3-6 months suggesting the need for an alternative treatment strategy $(4.14 \pm 1.25)$.

Consensus reasons for use of adjunctive and/or alternative therapeutic options included high risk for steroid toxicity $(4.23 \pm 0.92)$, systemic/extrapulmonary involvement $(2.55 \pm 1.95)$ or if long-duration therapy is anticipated (3.05 \pm 2.24$)$. Inhaled corticosteroids were considered appropriate therapy for symptomatic relief of cough $(3.45 \pm 1.22)$ and asthma-like symptoms $(3.77 \pm 1.11)$ but should be discontinued if ineffective or toxicities develop. 
TABLE 1 Characteristics of the Delphi panellists

\section{Characteristic}

Panellists n

\begin{tabular}{|c|c|}
\hline \multicolumn{2}{|l|}{ Specialty $\#$} \\
\hline Pulmonology & 19 \\
\hline Critical care & 3 \\
\hline Rheumatology & 2 \\
\hline Cardiology & 1 \\
\hline Oncology & 1 \\
\hline \multicolumn{2}{|c|}{ Experience treating sarcoidosis ${ }^{\natural}$} \\
\hline $6-10$ years & 5 \\
\hline $11-20$ years & 8 \\
\hline$>20$ years & 8 \\
\hline \multicolumn{2}{|c|}{ Patients with sarcoidosis treated in entire career ${ }^{\Uparrow}$} \\
\hline$\leqslant 500$ & 7 \\
\hline $501-1000$ & 8 \\
\hline $1001-3000$ & 3 \\
\hline$>3000$ & 2 \\
\hline \multicolumn{2}{|c|}{ Patients with sarcoidosis treated last year ${ }^{\natural}$} \\
\hline$\leqslant 50$ & 7 \\
\hline $51-100$ & 8 \\
\hline $101-300$ & 3 \\
\hline$>300$ & 2 \\
\hline
\end{tabular}

\#: highest degree of specialty is reported; ": some panellists did not respond to these questions.

Statement Mean士sD

\begin{tabular}{l} 
Initial therapy \\
\hline Initial treatment for pulmonary sarcoidosis should \\
usually be oral prednisone unless contraindicated \\
The starting dose should be decreased in the following \\
conditions: \\
Diabetes \\
Psychosis \\
Osteoporosis \\
Obesity \\
\hline $\begin{array}{l}\text { Adjustments in therapy based on changes in the } \\
\text { disease severity at follow-up }\end{array}$ Worsening \\
Adding/increasing adjunctive therapy \\
No adjustment is needed \\
Re-evaluate the diagnosis and treatment \\
Stable disease \\
Withdrawing the steroid \\
Decreasing the steroid dose\# \\
Improvement \\
Increasing the steroid dose \\
No adjustment is needed \\
Decreasing the steroid dose\#
\end{tabular}

FIGURE 2 Delphi consensus for initial therapy and adjustments in therapy of pulmonary sarcoidosis. Bold indicates statements that reached consensus. \#: dose decrease to find the lowest dose that provides satisfactory symptom relief and disease control. 


\section{Steroid-sparing alternatives}

There was no consensus on the use of steroid-sparing therapies for mild disease, although there was a trend toward disagreement with this strategy $(-1.27 \pm 2.75$, no consensus). For this item, mild disease was defined as mild to no symptoms or impairment of lung function, and no significant neurologic, cardiac or ocular findings $(3.55 \pm 1.47)$.

\section{Non-biologics: immunomodulators}

Panellists reached consensus on several reasons to consider non-biologic therapies, including severe disease $(3.18 \pm 2.22)$, inadequate response to steroid therapy $(4.27 \pm 0.94)$, expectation of prolonged and/or high-dose steroid therapy $(4.55 \pm 0.60)$, and the occurrence of steroid toxicity $(4.36 \pm 0.90)$. Methotrexate was the favoured initial non-biologic therapy (3.27 \pm 2.27$)$ with oral administration being favoured $(3.27 \pm 2.10)$ (figure 3 ). Subcutaneous administration was considered for nausea and other gastrointestinal side-effects (2.59 \pm 2.34$)$.

For treatment failure with non-biologics, there was consensus for switching to a biologic agent $(3.45 \pm 1.71)$ or discontinuation $(2.64 \pm 2.28)$, and near consensus for switching to an alternate non-biologic $(2.41 \pm 2.44)$. With toxicity to a non-biologic, switching to an alternate non-biologic $(3.55 \pm 1.18)$ or discontinuation $(3.00 \pm 1.38)$ reached consensus. With intolerability to a non-biologic, switching non-biologics $(3.82 \pm 1.01)$, discontinuing the non-biologic $(3.55 \pm 1.41)$, or switching to a biologic $(2.64 \pm 1.89)$ reached consensus. Patient preference $(3.18 \pm 1.40)$ or high patient cost $(3.32 \pm 1.67)$ were reasons to switch non-biologics. Intolerability $(4.55 \pm 0.67)$, toxicity $(4.50 \pm 0.96)$, failure to stabilise disease $(3.95 \pm 1.70)$ and long-term disease stabilisation $(2.50 \pm 2.28)$ were reasons for discontinuation. Combination non-biologic therapies were

Statement

\begin{tabular}{|c|c|c|c|c|c|c|}
\hline \multicolumn{7}{|l|}{ Non-biological immunomodulators } \\
\hline $\begin{array}{l}\text { For most patients, MTX should be the first } \\
\text { non-biologic used if it is not }\end{array}$ & $3.3 \pm 2.3$ & & & & & \\
\hline $\begin{array}{l}\text { For most patients, MTX should be } \\
\text { administered orally }\end{array}$ & $3.7 \pm 2.1$ & & & & & \\
\hline $\begin{array}{l}\text { For most patients, azathioprine should be } \\
\text { the first non-biologic used }\end{array}$ & $-1.4 \pm 2.1$ & & & & & \\
\hline $\begin{array}{l}\text { For most patients, azathioprine should be } \\
\text { tried if MTX has failed or is not tolerated }\end{array}$ & $1.9 \pm 2.6$ & & & & & \\
\hline $\begin{array}{l}\text { For most patients, mycophenolate should be } \\
\text { reserved for third-line therapy }\end{array}$ & $1.4 \pm 2.7$ & & & & & \\
\hline $\begin{array}{l}\text { For most patients, leflunomide should be } \\
\text { reserved for third-line therapy }\end{array}$ & $-0.4 \pm 3.2$ & & & : & & \\
\hline Biologic therapies & & -5.0 & -2.5 & 0.0 & 2.5 & 5.0 \\
\hline
\end{tabular}

Biologic therapies should be considered if:

\section{Severe or progressive disease is present}

Steroids amd non-biologics in combination are toxic or not sufficiently effective

Non-biologics are toxic or not sufficiently effective

Steroids are toxic or not sufficiently effective

For most patients, biologics should be used in combination with steroids

For most patients, biologics should be used in combination with steroids and non-biologics

\section{$3.7 \pm 1.4$}

$4.5 \pm 0.6$

$3.7 \pm 1.2$

$1.7 \pm 2.8$

$0.73 \pm 3.10$

$-0.23 \pm 2.76$

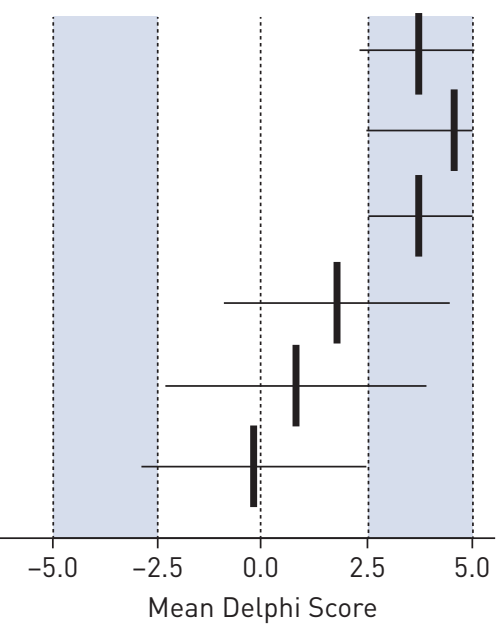

FIGURE 3 Likert scale consensus scores on use of selected non-biologic immunomodulators and biologic therapies. Bold indicates statements that reached consensus. MTX: methotrexate. 
considered for several clinical situations but did not reach consensus. The most favourable response for use of combination non-biological therapies was for improvement of response when a single drug gives only a partial response (1.95 \pm 2.63 , no consensus).

There was agreement that hydroxychloroquine may be useful in managing hypercalcaemia $(2.55 \pm 1.68)$ and skin disease $(3.41 \pm 1.33)$. Panellists did not reach consensus for use of azathioprine as first-line therapy $(-1.41 \pm 2.09)$ or, if methotrexate fails or is not tolerated $(1.91 \pm 2.56)$, mycophenolate as third-line therapy $(1.36 \pm 2.66)$ or leflunomide as third-line therapy $(-0.41 \pm 3.17)$ (figure 3). Although it did not reach consensus, there was agreement that chlorambucil has little role in treatment (2.55 \pm 3.02$)$. Panellists also did not arrive at consensus on the use of folic acid as an adjunctive therapy to non-biologics, although this suggestion achieved a relatively high non-consensus rating $(-2.00 \pm 2.51)$.

Several other therapeutic strategies for use of non-biologic immunomodulators did not reach consensus.

\section{Biologic therapies}

Use of biologic therapies reached consensus if non-biologics (alone or in combination with steroids) are toxic or insufficiently effective or if severe or progressive disease is present (figure 3). Tumour necrosis factor (TNF) inhibitors $(4.50 \pm 0.67)$ were the only biologics demonstrating consensus, with infliximab $(3.73 \pm 1.32)$ favoured with a loading dose of $5 \mathrm{mg} \cdot \mathrm{kg}^{-1}$ at weeks 0,2 and $6(2.86 \pm 2.32)$, but without consensus on maintenance dose. The highest rated maintenance regimen was $5 \mathrm{mg} \cdot \mathrm{kg}^{-1}$ every 4 weeks $(2.23 \pm 2.43)$. For most patients, biologics in combination with non-biologics $(2.50 \pm 2.28)$, typically methotrexate $(2.64 \pm 1.99)$ at a low-dose $(3.55 \pm 1.60)$, were considered beneficial in reducing risk of autoantibodies $(3.50 \pm 1.47)$. Other combinations were considered but did not reach consensus.

Discontinuation of biologic therapy is considered for treatment toxicity (4.14 \pm 1.93$)$, failure to achieve disease stabilisation $(3.73 \pm 1.91)$ or demonstration of disease stability for at least $2-3$ years $(3.64 \pm 1.36)$. Consensus was not reached on any specific strategy for weaning off biologics.

\section{Antibiotic prophylaxis}

Prophylaxis for Pneumocystis pneumonia was considered for specific patient populations, including patients receiving prolonged high-dose steroids $(2.77 \pm 3.15)$, high-dose immunosuppression with multiple agents (2.86 \pm 2.46$)$, and patients at risk for infection (2.73 \pm 2.37$)$. Prophylaxis for tuberculosis was recommended for patients with a positive interferon- $\gamma$ test $(2.77 \pm 2.56)$ and those with a history of tuberculosis or latent tuberculosis $(2.59 \pm 2.54)$. Panellists reached a strong consensus for the use of pneumococcal and influenza vaccination $(4.05 \pm 2.26)$.

\section{Other therapies}

Consensus was achieved for consideration of lung transplantation for patients with low and worsening pulmonary function tests $(3.77 \pm 2.00)$, severe disease unresponsive to therapy $(4.18 \pm 1.74)$ or pulmonary hypertension (3.59 \pm 2.44$)$.

\section{Discussion}

Large knowledge gaps persist regarding best treatment practices in sarcoidosis. We present results of an international Delphi effort involving 26 experts from seven countries: China $(n=1)$, France $(n=1)$, Germany $(n=2)$, Netherlands $(n=2)$, Sweden $(n=1)$, UK $(n=1)$, and USA $(n=18)$. While the majority of panellists were from the USA, experts with a range of experience and specialty training were included from around the world. The panel consisted of those with long standing interest in the disease, as well as those relatively new in the field. We did not perceive a difference in the responses based on country of origin or duration of experience with sarcoidosis.

The following key treatment concepts emerged from the Delphi process (figure 4). 1) Escalation of care based on disease progression. In acute presentations or those anticipated to develop into a chronic phenotype, prednisone 20-40 mg was the favoured medication, allowing 3-6 months to demonstrate responsiveness, after which escalation is considered. Escalation should usually consist of adding methotrexate to prednisone as a second-line therapy (with other options mentioned in case of toxicity or failure). The group then suggested escalation to biologics for those with advanced disease, with infliximab therapy favoured in this group. Continued lack of efficacy would bring consideration of repository corticotrophin injection or concomitant levofloxacin, ethambutol, azithromycin, rifampin (CLEAR) therapy, although no consensus was reached on use of these therapies. 2) Weaning prednisone to lowest tolerable dose. No specific dose was explored by this group, but a dose of $\leqslant 10 \mathrm{mg}$ has been suggested in the literature [31, 32]. 3) Escalation of care based on inability to wean prednisone to a lower dose, following essentially the same escalation steps delineated earlier. 


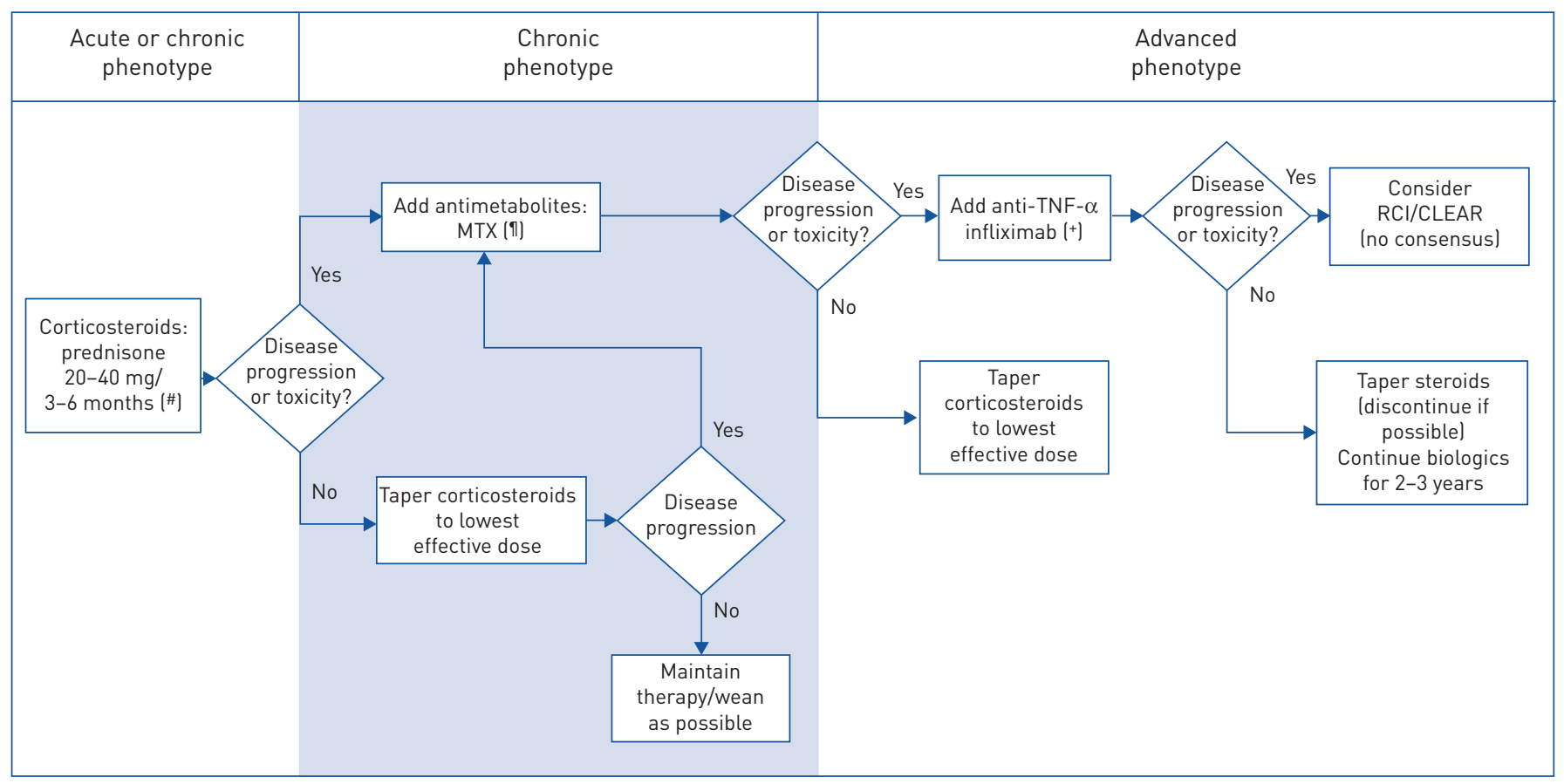

FIGURE 4 Treatment algorithm for symptomatic or organ-threatening sarcoidosis derived from the Delphi consensus recommendations. MTX: methotrexate; TNF- $\alpha$ : tumour necrosis factor- $\alpha$; CLEAR: concomitant levofloxacin, ethambutol, azithromycin and rifampin; RCl: repository corticotrophin injection. \#: consider hydroxychloroquine in cases of hypercalcemia or skin disease; " : alternatives considered that did not reach consensus: azathioprine, mycophenolate, leflunomide; ${ }^{+}$: alternatives considered that did not reach consensus: adalimumab, rituximab.

The proposed treatment algorithm highlights key concepts by sarcoidosis phenotype and is derived from the resulting Delphi consensus recommendations. Although phenotyping is arbitrary and other phenotyping approaches exist, we propose this algorithm as a method to assist the clinician in making treatment decisions.

There is an increasing amount of evidence supporting the use of several treatment regimens in sarcoidosis [33]. However, when and how to use these drugs remains unclear. The first section of the Delphi examined when to start systemic therapy for sarcoidosis. Nearly half of patients with sarcoidosis never require systemic treatment [34, 35]. There is little evidence that corticosteroid treatment in the asymptomatic pulmonary sarcoidosis patient changes the natural course of the disease $[36,37]$. However, treatment with corticosteroids has been shown to be effective in symptomatic disease [38-40]. The Delphi helped clarify recommendations for initiation of corticosteroid therapy.

Some groups have advocated prolonged use of corticosteroid monotherapy in the management of sarcoidosis [40, 41]. However, others have advocated the use of steroid-sparing agents in managing chronic disease [42]. A previous Delphi focused on the switch from prednisone to methotrexate [43]. This active, reactive and proactive approach is in contrast to what was promoted a few decades ago involving the use of prednisone monotherapy, eventually tapered to lower doses that could be managed chronically. This older approach failed to adequately address disease progression and the harm related to prolonged steroid use. Over the past few years, toxicity from prolonged use of even low doses of prednisone in sarcoidosis patients has been noted, including weight gain, steroid-induced complications and reduced quality of life [44-46]. These studies have emphasised the need to consider steroid-sparing alternatives. In the current Delphi, the indications for adding a second-line agent were addressed. Methotrexate was the most common second-line agent recommended by the panel. This finding is the same as the prior Delphi [43]. Methotrexate is the most widely studied drug for sarcoidosis, including a placebo-controlled randomised trial [47-49]. Compared to other cytotoxic agents, it is better tolerated $[49,50]$. Recommendations of when and how to use methotrexate in sarcoidosis have been developed [51].

Consensus recommendations regarding when to move to a third agent were developed. The biologics, especially monoclonal antibodies to TNFs, have changed the approach to advanced disease over the past 10 years [52]. The panel achieved consensus on some of the possible indications for adding a biologic agent (toxicity, insufficient response, and severe or progressive disease). The panel agreed that infliximab was the first choice as a biologic agent. This anti-TNF- $\alpha$ monoclonal antibody has multiple clinical trials supporting its use in various manifestations of sarcoidosis [53-56]. Of the other anti-TNF antibodies, 
adalimumab has been found to be effective in some patients [57-59]. Other anti-TNF agents such as golimumab and etanercept were not found to be effective in most sarcoidosis patients [60-62].

The panel also considered the use of rituximab, another biologic agent. Previous studies have reported some effectiveness for rituximab in treating sarcoidosis $[15,63,64]$. To date, the data are limited for this agent and the Delphi results reflect the lack of information on this drug. The use of repository corticotrophin is the focus of another Delphi article.

The Delphi panel did look at managing complications from treatment. This is an area with limited information. Guidelines for specific agents such as methotrexate and the anti-TNF agents have been developed [51, 52, 65]. Fortunately, most sarcoidosis patients do not acquire opportunistic infections despite prolonged immunosuppressive therapy $[66,67]$. One of the recommendations of the panel was the use of pneumocystis prophylaxis in patients on high-dose immunosuppression. The criteria for high dose was not specified by the Delphi panellists because of a lack of agreement regarding the many different drug combinations. An example of high-dose immunosuppression would be $\geqslant 20 \mathrm{mg}$ prednisone with a cytotoxic agent for $>6$ months. This is an area in which further research is needed.

The Delphi method is a broadly accepted strategy for developing consensus recommendations based on objective expert opinion and is intended to provide guidance in areas where limited evidence-based literature is available. A key strength of the Delphi method is its use of a systematic, anonymous process that promotes free sharing of opinions and ideas, weighs all panellists' opinions equally, and makes it difficult for any individual panellist to dominate the process. Electronic communications were used to collect and disseminate information. This methodology helps maintain the anonymous nature of the Delphi process.

The Delphi methodology dates back to the 1950s and was developed to create consensus in social science topics $[20-25,43]$. The methodology is particularly relevant when there is real knowledge available on a particular topic, but definitive experiments to prove the point are lacking. However, the Delphi process has several limitations. There are no generally accepted criteria defining consensus in Delphi studies and, given the wide variety of topics investigated using the Delphi approach, it may not be possible to define generally applicable criteria $[21,22,68]$. Clearly the consensus only represents a degree of agreement among the experts and may be refuted in the future by rigorous studies [22, 24, 68]. Panellist selection and the development of the initial questionnaire may have inadvertently introduced bias into the process [23, 69]. As clinical aspects of sarcoidosis are deeply influenced by genetics and geographical province of patients, including an unbalanced geographic dispersion of panellists may have also inadvertently introduced bias. We attempted to maximise neutrality and avoid any intrusion of bias in the selection of the panellists.

Anonymity is an important aspect of the Delphi process, intended to prevent bias by influential or forceful panellists and reduce pressure on panellists to conform. Conversely, it means that panellists are not accountable for their responses, possibly leading to responses based on insufficient or minimal consideration [68]. The panellists had a wide range of experience while satisfying the inclusion criteria. The differing levels of expertise related to the study may help ensure a real-world reflection of prescribers and, therefore, allow the article to capture a full range of practice opinions [70].

\section{Conclusion}

While there was significant variance in the treatment of sarcoidosis, this exercise did identify several areas for which there is consensus. The exercise also identified several potential areas where future studies may provide clarity.

Conflict of interest: F.F. Rahaghi reports grants and consulting fees from Mallinckrodt, during the conduct of the study. R.P. Baughman reports grants and personal fees from Mallinckrodt, Novartis and Celgene, grants from Gilead, Genentech, Bayer and West Pharmaceutical, during the conduct of the study. L.A. Saketkoo has nothing to disclose. N.J. Sweiss has nothing to disclose. J.B. Barney has nothing to disclose. S.S. Birring has nothing to disclose. U. Costabel has nothing to disclose. E.D. Crouser has no relevant conflicts of interest to disclose. M. Drent has nothing to disclose. A.K. Gerke has nothing to disclose. J.C. Grutters has nothing to disclose. N.Y. Hamzeh has a patent pending from Prothena Inc. I. Huizar has no relevant conflicts of interest to disclose. W.E. James has nothing to disclose. S. Kalra has nothing to disclose. S. Kullberg has nothing to disclose. H. Li has nothing to disclose. E.E. Lower has nothing to disclose. L.A. Maier reports grants from National Institutes of Health: 1R01 HL127461-01A, 1R01HL11487-01A1, R01HL136681-01A1, 1R21 128738A-02, R21 HL140012-1, outside the submitted work. M. Mirsaeidi reports grants and personal fees from Mallinckrodt, outside the submitted work. J. Müller-Quernheim has nothing to disclose. E.M. Carmona Porquera reports other from ReSaph (Gilead), personal fees from American College of Chest Physicians (CHEST), outside the submitted work. L. Samavati participated in the Questcor Advisory Board Meeting 2014 and received \$6500 compensation. D. Valeyre reports personal fees from Roche, Boehringer Ingelheim, AstraZeneca and Boehringer Ingelheim, outside the submitted work. M.B. Scholand reports other from Boehringer Ingelheim, Fibrogen, Global Blood Therapeutics and Genetech, outside the submitted work. In addition, M.B. Scholand has a patent 
Apparatus, Compositions and Methods for Assessment of Chronic Obstructive Pulmonary Disease Progression among Rapid and Slow Decline Conditions issued.

\section{References}

1 Baughman RP, Nunes H. Therapy for sarcoidosis: evidence-based recommendations. Expert Rev Clin Immunol 2012; 8: 95-103.

2 Jeny F, Bouvry D, Freynet O, et al. Management of sarcoidosis in clinical practice. Eur Respir Rev 2016; 25 $141-150$.

3 Nunes H, Bouvry D, Soler P, et al. Sarcoidosis. Orphanet J Rare Dis 2007; 2: 46.

4 Arkema EV, Cozier YC. Epidemiology of sarcoidosis: current findings and future directions. Ther Adv Chronic Dis 2018; 9: 227-240.

5 Baughman RP, Field S, Costabel U, et al. Sarcoidosis in America. Analysis based on health care use. Ann Am Thorac Soc 2016; 13: 1244-1252.

6 Beghe D, Dall'Asta L, Garavelli C, et al. Sarcoidosis in an Italian province. Prevalence and environmental risk factors. PLoS One 2017; 12: e0176859.

7 Coquart N, Cadelis G, Tressieres B, et al. Epidemiology of sarcoidosis in Afro-Caribbean people: a 7-year retrospective study in Guadeloupe. Int J Dermatol 2015; 54: 188-192.

8 Duchemann B, Annesi-Maesano I, Jacobe de Naurois C, et al. Prevalence and incidence of interstitial lung diseases in a multi-ethnic county of Greater Paris. Eur Respir J 2017; 50: 1602419.

9 Dumas O, Abramovitz L, Wiley AS, et al. Epidemiology of sarcoidosis in a prospective cohort study of U.S. women. Ann Am Thorac Soc 2016; 13: 67-71.

10 Ungprasert P, Crowson CS, Matteson EL. Influence of gender on epidemiology and clinical manifestations of sarcoidosis: a population-based retrospective cohort study 1976-2013. Lung 2017; 195: 87-91.

$11 \mathrm{Wu} \mathrm{CH}$, Chung PI, Wu CY, et al. Comorbid autoimmune diseases in patients with sarcoidosis: a nationwide case-control study in Taiwan. J Dermatol 2017; 44: 423-430.

12 Hattori T, Konno S, Shijubo N, et al. Resolution rate of pulmonary sarcoidosis and its related factors in a Japanese population. Respirology 2017; 22: 1604-1608.

13 Saketkoo LA, Baughman RP. Biologic therapies in the treatment of sarcoidosis. Expert Rev Clin Immunol 2016; 12 $817-825$.

14 Gerke AK. Morbidity and mortality in sarcoidosis. Curr Opin Pulm Med 2014; 20: 472-478.

15 Sweiss NJ, Lower EE, Mirsaeidi M, et al. Rituximab in the treatment of refractory pulmonary sarcoidosis. Eur Respir J 2014; 43: 1525-1528.

16 Baughman RP, Nunes H, Sweiss NJ, et al. Established and experimental medical therapy of pulmonary sarcoidosis. Eur Respir J 2013; 41: 1424-1438.

17 Paramothayan NS, Lasserson TJ, Jones PW. Corticosteroids for pulmonary sarcoidosis. Cochrane Database Syst Rev 2005; 2: CD001114.

18 Paramothayan S, Lasserson TJ, Walters EH. Immunosuppressive and cytotoxic therapy for pulmonary sarcoidosis. Cochrane Database Syst Rev 2006; 3: CD003536.

19 Paramothayan S, Lasserson T. Treatments for pulmonary sarcoidosis. Respir Med 2008; 102: 1-9.

20 Pietersma S, de Vries M, van den Akker-van Marle ME. Domains of quality of life: results of a three-stage Delphi consensus procedure among patients, family of patients, clinicians, scientists and the general public. Qual Life Res 2014; 23: 1543-1556.

21 Phillips AC, Lewis LK, McEvoy MP, et al. Protocol for development of the guideline for reporting evidence based practice educational interventions and teaching (GREET) statement. BMC Med Educ 2013; 13: 9.

22 Phillips AC, Lewis LK, McEvoy MP, et al. A Delphi survey to determine how educational interventions for evidence-based practice should be reported: stage 2 of the development of a reporting guideline. BMC Med Educ 2014; 14: 159 .

23 Mansell G, Shapley M, van der Windt D, et al. Critical items for assessing risk of lung and colorectal cancer in primary care: a Delphi study. Br J Gen Pract 2014; 64: e509-e515.

$24 \mathrm{Li} \mathrm{Y}$, Ehiri J, Hu D, et al. Framework of behavioral indicators for outcome evaluation of TB health promotion: a Delphi study of TB suspects and TB patients. BMC Infect Dis 2014; 14: 268.

25 Haines S, Baker T, Donaldson M. Development of a physical performance assessment checklist for athletes who sustained a lower extremity injury in preparation for return to sport: a Delphi study. Int J Sports Phys Ther 2013; 8: $44-53$

26 Distler O, Behrens F, Pittrow D, et al. Defining appropriate outcome measures in pulmonary arterial hypertension related to systemic sclerosis: a Delphi consensus study with cluster analysis. Arthritis Rheum 2008; 59: $867-875$

27 Huscher D, Pittrow D, Distler O, et al. Interactions between rheumatologists and cardio-/pulmonologists in the assessment and use of outcome measures in pulmonary arterial hypertension related to systemic sclerosis. Clin Exp Rheumatol 2010; 28: Suppl. 58, S47-S52.

28 Saketkoo LA, Mittoo S, Huscher D, et al. Connective tissue disease related interstitial lung diseases and idiopathic pulmonary fibrosis: provisional core sets of domains and instruments for use in clinical trials. Thorax 2014; 69: $428-436$.

29 Rahaghi FF, Feldman JP, Allen RP, et al. Recommendations for the use of oral treprostinil in clinical practice: a Delphi consensus project pulmonary circulation. Pulm Circ 2017; 7: 167-174.

30 Rahaghi FF, Alnuaimat HM, Awdish RLA, et al. Recommendations for the clinical management of patients receiving macitentan for pulmonary arterial hypertension (PAH): a Delphi consensus document. Pulm Circ 2017; 7: 702-711.

31 Hunninghake GW, Costabel U, Ando M, et al. American Thoracic Society/European Respiratory Society/World Association of Sarcoidosis and other Granulomatous Disorders. Sarcoidosis Vasc Diffuse Lung Dis 1999; 16: 149-173.

32 McKinzie BP, Bullington WM, Mazur JE, et al. Efficacy of short-course, low-dose corticosteroid therapy for acute pulmonary sarcoidosis exacerbations. Am J Med Sci 2010; 339: 1-4.

33 James WE, Baughman R. Treatment of sarcoidosis: grading the evidence. Expert Rev Clin Pharmacol 2018; 11: 677-687. 
34 Baughman RP, Judson MA, Teirstein A, et al. Presenting characteristics as predictors of duration of treatment in sarcoidosis. QJM 2006; 99: 307-315.

35 Hunninghake GW, Gilbert S, Pueringer R, et al. Outcome of the treatment for sarcoidosis. Am J Respir Crit Care Med 1994; 149: 893-898.

36 Gibson GJ, Prescott RJ, Muers MF, et al. British Thoracic Society Sarcoidosis study: effects of long term corticosteroid treatment. Thorax 1996; 51: 238-247.

37 Pietinalho A, Tukiainen P, Haahtela T, et al. Oral prednisolone followed by inhaled budesonide in newly diagnosed pulmonary sarcoidosis: a double-blind, placebo-controlled multicenter study. Finnish Pulmonary Sarcoidosis Study Group. Chest 1999; 116: 424-431.

38 Pietinalho A, Tukiainen P, Haahtela T, et al. Early treatment of stage II sarcoidosis improves 5-year pulmonary function. Chest 2002; 121: 24-31.

39 James DG, Carstairs LS, Trowell J, et al. Treatment of sarcoidosis. Report of a controlled therapeutic trial. Lancet 1967; 2: 526-528.

40 Johns CJ, Michele TM. The clinical management of sarcoidosis. A 50-year experience at the Johns Hopkins Hospital. Medicine (Baltimore) 1999; 78: 65-111.

41 Moller DR. Negative clinical trials in sarcoidosis: failed therapies or flawed study design? Eur Respir J 2014; 44: 1123-1126.

42 Baughman RP, Grutters JC. New treatment strategies for pulmonary sarcoidosis: antimetabolites, biological drugs, and other treatment approaches. Lancet Respir Med 2015; 3: 813-822.

43 Schutt AC, Bullington WM, Judson MA. Pharmacotherapy for pulmonary sarcoidosis: a Delphi consensus study. Respir Med 2010; 104: 717-723.

44 Broos CE, Poell LHC, Looman CWN, et al. No evidence found for an association between prednisone dose and FVC change in newly-treated pulmonary sarcoidosis. Respir Med 2018; 138S: S31-S37.

45 Khan NA, Donatelli CV, Tonelli AR, et al. Toxicity risk from glucocorticoids in sarcoidosis patients. Respir Med 2017; 132: 9-14.

46 Judson MA, Chaudhry H, Louis A, et al. The effect of corticosteroids on quality of life in a sarcoidosis clinic: the results of a propensity analysis. Respir Med 2015; 109: 526-531.

47 Baughman RP, Winget DB, Lower EE. Methotrexate is steroid sparing in acute sarcoidosis: results of a double blind, randomized trial. Sarcoidosis Vasc Diffuse Lung Dis 2000; 17: 60-66.

48 Lower EE, Baughman RP. Prolonged use of methotrexate for sarcoidosis. Arch Intern Med 1995; 155: 846-851.

49 Bitoun S, Bouvry D, Borie R, et al. Treatment of neurosarcoidosis: a comparative study of methotrexate and mycophenolate mofetil. Neurology 2016; 87: 2517-2521.

50 Vorselaars ADM, Wuyts WA, Vorselaars VMM, et al. Methotrexate vs azathioprine in second-line therapy of sarcoidosis. Chest 2013; 144: 805-812.

51 Cremers JP, Drent M, Bast A, et al. Multinational evidence-based World Association of Sarcoidosis and Other Granulomatous Disorders recommendations for the use of methotrexate in sarcoidosis: integrating systematic literature research and expert opinion of sarcoidologists worldwide. Curr Opin Pulm Med 2013; 19: 545-561.

52 Drent M, Cremers JP, Jansen TL, et al. Practical eminence and experience-based recommendations for use of TNF-alpha inhibitors in sarcoidosis. Sarcoidosis Vasc Diffuse Lung Dis 2014; 31: 91-107.

53 Baughman RP, Drent M, Kavuru M, et al. Infliximab therapy in patients with chronic sarcoidosis and pulmonary involvement. Am J Respir Crit Care Med 2006; 174: 795-802.

54 Jamilloux Y, Cohen-Aubart F, Chapelon-Abric C, et al. Efficacy and safety of tumor necrosis factor antagonists in refractory sarcoidosis: a multicenter study of 132 patients. Semin Arthritis Rheum 2017; 47: $288-294$.

55 Gelfand JM, Bradshaw MJ, Stern BJ, et al. Infliximab for the treatment of CNS sarcoidosis: a multi-institutional series. Neurology 2017; 89: 2092-2100.

56 Baughman RP, Judson MA, Lower EE, et al. Infliximab for chronic cutaneous sarcoidosis: a subset analysis from a double-blind randomized clinical trial. Sarcoidosis Vasc Diffuse Lung Dis 2016; 32: 289-295.

57 Crommelin HA, van der Burg LM, Vorselaars AD, et al. Efficacy of adalimumab in sarcoidosis patients who developed intolerance to infliximab. Respir Med 2016; 115: 72-77.

58 Sweiss NJ, Noth I, Mirsaeidi M, et al. Efficacy results of a 52-week trial of adalimumab in the treatment of refractory sarcoidosis. Sarcoidosis Vasc Diffuse Lung Dis 2014; 31: 46-54.

59 Pariser RJ, Paul J, Hirano S, et al. A double-blind, randomized, placebo-controlled trial of adalimumab in the treatment of cutaneous sarcoidosis. I Am Acad Dermatol 2013; 68: 765-773.

60 Baughman RP, Lower EE, Bradley DA, et al. Etanercept for refractory ocular sarcoidosis: results of a double-blind randomized trial. Chest 2005; 128: 1062-1067.

61 Utz JP, Limper AH, Kalra S, et al. Etanercept for the treatment of stage II and III progressive pulmonary sarcoidosis. Chest 2003; 124: 177-185.

62 Judson MA, Baughman RP, Costabel U, et al. Safety and efficacy of ustekinumab or golimumab in patients with chronic sarcoidosis. Eur Respir J 2014; 44: 1296-1307.

63 Zella S, Kneiphof J, Haghikia A, et al. Successful therapy with rituximab in three patients with probable neurosarcoidosis. Ther Adv Neurol Disord 2018; 11: 1756286418805732.

64 Cinetto F, Compagno N, Scarpa R, et al. Rituximab in refractory sarcoidosis: a single centre experience. Clin Mol Allergy 2015; 13: 19.

65 Baughman RP, Meyer KC, Nathanson I, et al. Monitoring of nonsteroidal immunosuppressive drugs in patients with lung disease and lung transplant recipients: American College of Chest Physicians evidence-based clinical practice guidelines. Chest 2012; 142: e1S-e111S.

66 Baughman RP, Lower EE. Fungal infections as a complication of therapy for sarcoidosis. QJM 2005; 98: 451-456.

67 Jamilloux Y, Valeyre D, Lortholary O, et al. The spectrum of opportunistic diseases complicating sarcoidosis. Autoimmun Rev 2015; 14: 64-74.

68 Powell C. The Delphi technique: myths and realities. J Adv Nurs 2003; 41: 376-382.

69 Hasson F, Keeney S, McKenna H. Research guidelines for the Delphi survey technique. J Adv Nurs 2000; 32: 1008-1015

70 Hsu CC, Sandford BA. The Delphi technique: making sense of consensus. Pract Assess Res Eval 2007; 12: 1-8. 